Correction

\title{
Correction: Ono, S.; Lam, S.; Nagahara, M.; Hoon, D.S.B. Circulating microRNA Biomarkers as Liquid Biopsy for Cancer Patients: Pros and Cons of Current Assays. J. Clin. Med. 2015, 4, 1890-1907
}

\author{
Shigeshi Ono, Stella Lam, Makoto Nagahara and Dave S. B. Hoon *
}

Department of Molecular Oncology, John Wayne Cancer Institute, Providence Saint John's Health Center, 2200 Santa Monica Blvd., Santa Monica, CA 90404, USA; onos@jwci.org (S.O.); lams@jwci.org (S.L.); Nagahara.srg2@tmd.ac.jp (M.N.)

* Correspondence: hoond@jwci.org; Tel.: +1-310-449-5267

Academic Editor: Jane Grant-Kels

Received: 31 August 2016; Accepted: 31 August 2016; Published: 12 September 2016

The authors wish to make the following corrections to this paper [1]:

Table 4. Summary of microarrays for cmiRNA.

\begin{tabular}{ccc}
\hline Assay & Required Input (ng) & Probe Content \\
\hline Affymetrix GeneChip miRNA Arrays 4.0 & 130 & miRBase v.20 \\
Agilent oligonucleotides microarrays & 100 & miRBase v.21 \\
Exiqon miRCURY LNA microRNA arrays & 30 & miRBase v.19 \\
$\mu$ Paraflo ${ }^{\circledR}$ Microfluidic Biochip Technology & 1000 & miRBase v.21 \\
3D-Gene ${ }^{\circledR}$ & 2000 & miRBase v.21 \\
\hline
\end{tabular}

should be replaced with

Table 4. Summary of microarrays for cmiRNA.

\begin{tabular}{ccc}
\hline Assay & Required Input (ng) & Probe Content \\
\hline Affymetrix GeneChip miRNA Arrays 4.0 & 130 & miRBase v.20 \\
Agilent oligonucleotides microarrays & 100 & miRBase v.21 \\
Exiqon miRCURY LNA microRNA arrays & 30 & miRBase v.19 \\
$\mu$ Paraflo ${ }^{\circledR}$ Microfluidic Biochip Technology & 1000 & miRBase v.21 \\
3D-Gene ${ }^{\circledR}$ & 250 & miRBase v.21 \\
\hline
\end{tabular}

The authors apologize for any inconvenience caused to the readers by these changes.

\section{Reference}

1. Ono, S.; Lam, S.; Nagahara, M.; Hoon, D.S.B. Circulating microRNA Biomarkers as Liquid Biopsy for Cancer Patients: Pros and Cons of Current Assays. J. Clin. Med. 2015, 4, 1890-1907. [CrossRef] [PubMed]

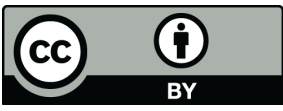

(C) 2016 by the authors; licensee MDPI, Basel, Switzerland. This article is an open access article distributed under the terms and conditions of the Creative Commons Attribution (CC-BY) license (http://creativecommons.org/licenses/by/4.0/). 